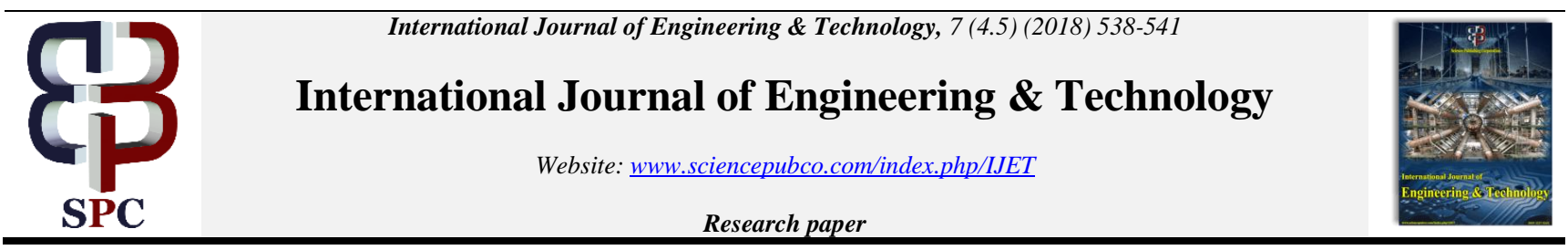

\title{
Investigation on properties of part fabricated by selective laser sintering (SLS) process
}

\author{
E. soundrapandian ${ }^{1}$, G. SenthilKumar ${ }^{2}$, A. Tajdeen ${ }^{1}$, P. Vivekkumar ${ }^{1}$ \\ ${ }^{1}$ Assistant Professors Department of Mechanical Engineering Bannari Amman Institute of Technology Sathyamangalam, Erode- \\ 638401 \\ ${ }^{2}$ Associate Professor Department of Mechanical Engineering Bannari Amman Institute of Technology Sathyamangalam, Erode- \\ 638401 \\ *Corresponding author E-mail: soundrapandian@bitsathy.ac.in
}

\begin{abstract}
Additive manufacturing (AM) can be used without the need of any moulds or tooling, and are very suitable for manufacturing one-piece or small batches of with complex external shapes and internal structures within a short lead time, which are difficult to make or even cannot be fabricated by the tooling and machining processes. The manufacturing of metal parts by sand casting method is a tedious process when considering low volume manufacturing where it took lot of time, design cost, material cost etc., In this paper, the web gland component has been prepared using stainless steel by varying the different process parameters such as scan spacing, laser power and layer thickness in selective laser sintering (SLS) process. By using vickers hardness tester, the hardness and the microstructure of component also analyzed and it is compared with the same component properties prepared by using sand casting process. From the comparative result, it was found that the hardness of material increases by $12.5 \%$ on sintered part than casting part.
\end{abstract}

Keywords: Use about five key words or phrases in alphabetical order, Separated by Semicolon.

\section{Introduction}

Additive manufacturing is a relatively novel idea to fabricate complex, net-shaped metal components in successive layers. As a rapid prototyping technique, short lead-times are obtained and design changes can easily be incorporated. By omitting extensive machining, material costs and scrap can be reduced, leading to a lower environmental impact with a good economic balance.

Metal deposition additive manufacturing technique was under investigation: There is no single consensus on the most appropriate method to develop suitable materials for laser sintering (3) and it is clear that no single property will provide an overall characterization however there are some core material characteristics that have been identified as key for successful laser sintering. Shaped metal deposition (1) allows the production of large and dense Ti-6Al-4V components with different shapes. In a single run, wall widths between 5 and $20 \mathrm{~mm}$ can be achieved.

A top and a bottom region can be discerned for all components, where the Widmanstätten microstructure consists of fine a lamellae in the top and coarse lamellae in the bottom region. The mechanical properties are competitive to cast material and components built by other additive manufacturing techniques. The UTS varies between 929 and $1014 \mathrm{MPa}$, depending on orientation and location of the specimens. Generally, the strain at failure is two to three times larger in $\mathrm{V}$ than in $\mathrm{H}$ direction. The differences in the UTS and strain at failure can be related to the lath size and to the orientation of the elongated, prior $b$ grains.

The gas permeability of the porous structure of an injection-molding die is affected by laser condition used in selective laser sintering. The metal powder mixture of alloy steel, copper phosphorous and nickel powders with an average particle diameter of $25 \mathrm{~m}$ was used. A fiber laser (wavelength $1070 \mathrm{~nm}$ ) was used to consolidate the metal powder, thus making any differences in the consolidation of the metal powder strongly related to the energy density under which was irradiated varying from fully melted to a fully sintered condition with decreasing energy density. Experiments also were carried out with a nominal $40 \mathrm{~W} \mathrm{CO}_{2}$ laser, on samples characterized by different particle size distributions within 16 and $184 \mu \mathrm{m}$, and different laser scan speeds (1 to $30 \mathrm{~mm} / \mathrm{s}$ ).

The energy required for the sintering process depends on the particle size (3-5). In the post processing of selective laser sintering process a theoretical model applied for the LMH interaction with metal powders attributes a magnetic heating effect also to powders made of non-magnetic metals, due to eddy currents. Micro-plasma discharges between the powder particles initiate their heating process. The additive $\mathrm{LMH}$ was intended to extend microwave sintering capabilities, mainly known in volumetric moulds, also to applications in the framework of rapid prototyping, additive manufacturing, and 3D-printing (2).

\section{Designing/selection of component}

The web casting is one of the part in C427 type internal valve assembly used in LPG storage during LPG transportation. The web casting is a part act as a guide to stem assembly. From the number of parts in the assembly part number 36 is selected as the part for study. The details and specifications of the part number 36 is explained in the following. The part number 36 acts as a guide for part number [2] (i.e. stem assembly). The design of web casting is shown as follows. 

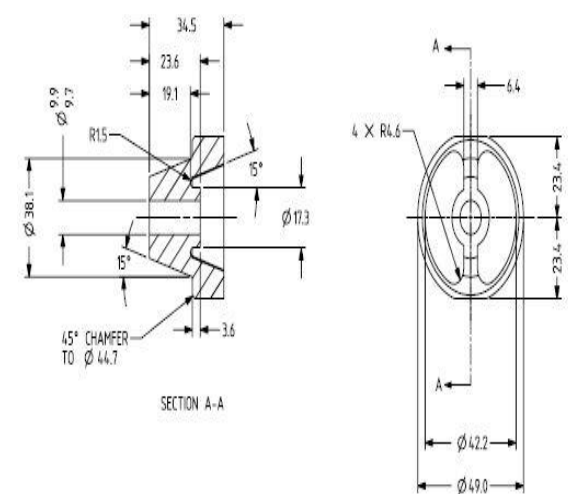

Fig. 2.1: Web Casting.

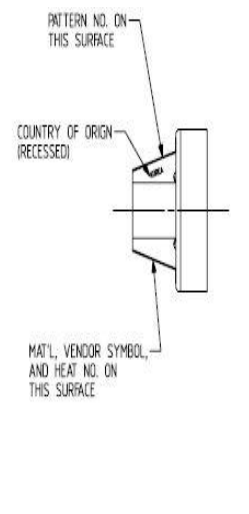

NX for Design is an integrated product design solution that streamlines and accelerates the product development process for engineers who need to deliver innovative products in a collaborative environment. NX for design offers the highest level of integration between development disciplines in an open, collaborative environment. The $\mathrm{CAD}$ model for the web of given dimensions were designed using NX CAD software as shown in the figure.

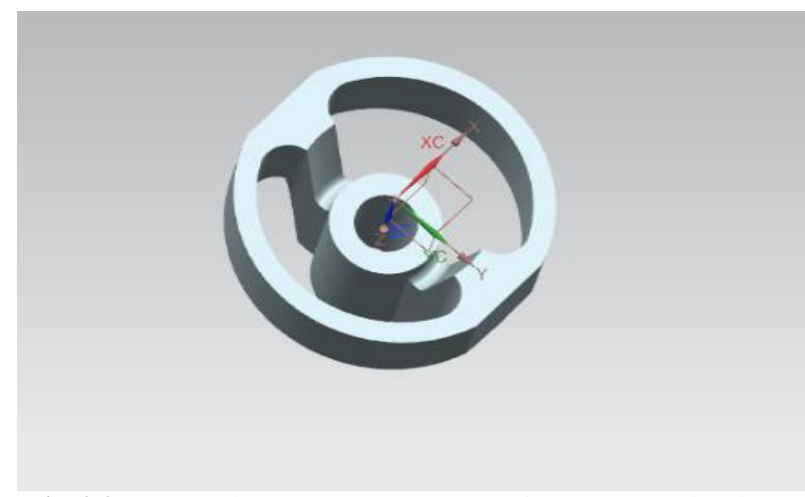

Fig. 2.2: Web Designed by NX CAD 3D Software (Isometric View).

\section{Fabrication of web casting by selective laser sintering process}

Selective laser sintering (SLS) is an additive manufacturing technique that uses a high power laser (for example, a carbon dioxide laser) to fuse small particles of plastic, metal (direct metal laser sintering), ceramic, or glass powders into a mass that has a desired 3 dimensional shape. The laser selectively fuses powdered material by scanning cross-sections generated from a 3-D digital description of the part (for example from a CAD file. SLS parts are ideally used for form, fit, function, and direct manufacturing applications. Machine Specification:

Machine: SLS Sinter station 2500+

Build Dimension: 381 x 330 x $457 \mathrm{~mm}$

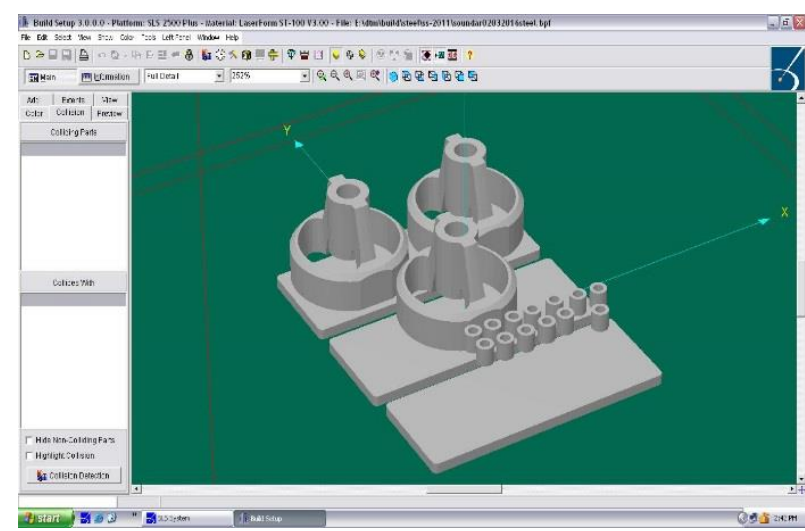

Fig. 3.1: Web in SLS Built Setup Software.

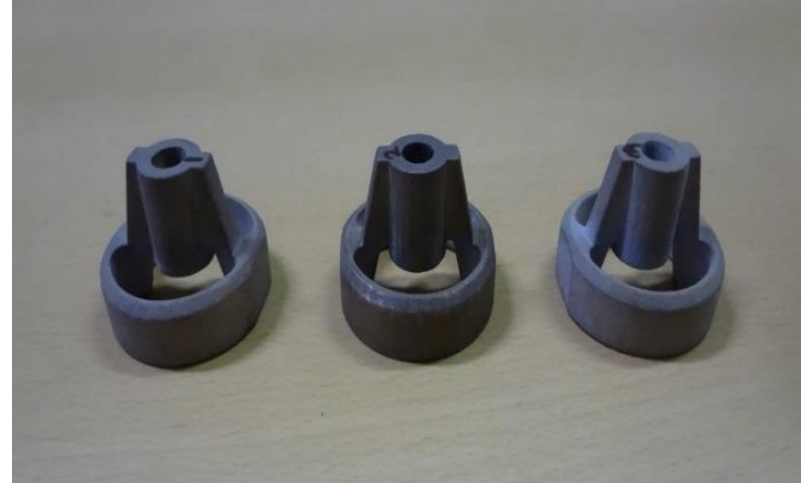

Fig. 3.2: Selective Laser Sintered Part.

Controlled Process Parameter

The laser radiation interaction with stainless steel, high scanning speed and distance scanning improve the cohesion characteristics of the layer obtained. The double laser beam technology, improves the ductile character of the metallic material obtained when the part is melted and solidified by the laser wave. When the scanned area increases, the rugosity of the surface is improved and side pores form. The following table explains the various control parameters with their values taken for study.

Table 1: Controlled Process Parameter Table

\begin{tabular}{lllll}
\multicolumn{5}{l}{ Table 1: Controlled Process Parameter Table } \\
\hline $\begin{array}{l}\text { Compo- } \\
\text { nent No }\end{array}$ & \multicolumn{2}{l}{ Process Parameter } & & \\
\hline & $\begin{array}{l}\text { Layer Thick- } \\
\text { ness (Mm) }\end{array}$ & $\begin{array}{l}\text { Laser } \\
\text { Power }\end{array}$ & $\begin{array}{l}\text { Bed Tem- } \\
\text { perature } \\
(\mathrm{W})\end{array}$ & $\begin{array}{l}\text { Scan Spac- } \\
\text { ing (Mm) }\end{array}$ \\
& 0.8 & 60 & 100 & 0.10 \\
1 & 1.0 & 64 & 100 & 0.10 \\
2 & 1.2 & 60 & 100 & 0.08 \\
3 & & & & \\
\hline
\end{tabular}

\section{Post-Processing}

Infiltration is the process of filling the pores of a sintered or unsintered $\mathrm{P} / \mathrm{M}$ compact with a metal or alloy of a lower melting point than the base metal. The infiltration process normally increases part density, strength, toughness, hardness and thermal and electrical conductivity. It was shown that infiltration to near theoretical densities was possible in several Fe-C based alloy systems. The necessary processing conditions generally included temperatures below $1200^{\circ} \mathrm{C}\left(2190^{\circ} \mathrm{F}\right)$, times of less than $1 / 2$ hour and the use of standard hydrogen-nitrogen atmospheres with modest methane additions to control the carbon potential (typically less than $0.5 \mathrm{v} / \mathrm{o}$ ). The required infiltrant composition was at or near the corresponding eutectic liquidus value of the selected alloy system and the required base compact composition was likewise at or near the eutectic solidus value. The possibility to combine an infiltrant composition of one alloy system with a base compact composition of another system was also demonstrated. In addition, it was shown that base compact densities of $6.8 \mathrm{~g} / \mathrm{cm}^{3}$ or less were sufficient to obtain a virtually pore free density after infiltration. The optimum base compact density in terms of maximizing the infiltration rate and minimizing the infiltrant weight to full density was determined to be about $6.7 \mathrm{~g} / \mathrm{cm}^{3}$.

Based on data from your CAD file, the SLS system deposits layer after layer of powder, sintering (heating and bonding) select portions to create the part. When the process is complete, sinter the part and infiltrate it with bronze, for a fully dense part with characteristics similar to steel. After printing is complete, the parts are cured in an oven, which enables the parts to be handled. After curing, the parts are sintered and infiltrated with bronze. Cool down can be varied to control the machinability and hardness of the material. The printed part is infiltrated because the green will have lesser strength so it has to be infiltrated with bronze. $30 \%$ of bronze was infiltrated in the green part. The infiltrated part was cured in crucible with alumina. Alumina is used to conduct the heat generated inside the crucible and prevent the shape of the part. During infiltration the part 
will be heated to $1050^{\circ} \mathrm{C}$ for about 2 hours, then the heat was increased to 1060 and 1080 hours. After gradual heating the part was cooled in room temperature for about 8 hours.

\section{Material testing}

Samples of engineering materials are subjected to a wide variety of mechanical tests to measure their strength, elastic constants, and other material properties as well as their performance under a variety of actual use conditions and environments. The results of such tests are used for two primary purposes: 1) engineering design (for example, failure theories based on strength, or deflections based on elastic constants and component geometry). 2) Quality control either by the materials producer to verify the process or by the end user to confirm the material specifications. Because of the need to compare measured properties and performance on a common basis, users and producers of materials use standardized test methods such as those developed by the American Society for Testing and Materials (ASTM) and the International Organization for Standardization (ISO).

Web Casting Manufactured By Casting Process

The following test results are obtained by conducting mechanical testing on the web casting.

Table 2: Test Result of Web Casting

\begin{tabular}{llll}
\hline \multicolumn{5}{c}{ Table 2: Test Result of Web Casting } \\
\hline Uts (Mpa) & $\begin{array}{l}\text { Yield Strength } \\
(\mathrm{Mpa})\end{array}$ & Elongation (\%) & Hardness \\
\hline 576.46 & 370.07 & 26.08 & 168 \\
\hline
\end{tabular}

Web Casting Manufactured By Selective Laser Sintering Process Hardness Test

The following are the hardness test result of the web fabricated by selective laser sintering process. The hardness test was carried out in Vickers hardness machine for a load of $1 \mathrm{KG}$. The table below shows the hardness value of the following parameters and values.

Table 3: Vickers Hardness Values of the Samples

\begin{tabular}{lllll}
\hline $\begin{array}{l}\text { Sample Descrip- } \\
\text { tion }\end{array}$ & $\begin{array}{l}\text { Sample } \\
\text { Number }\end{array}$ & $\begin{array}{l}\text { Hardness } \\
\text { value 1 }\end{array}$ & $\begin{array}{l}\text { Hardness } \\
\text { value 2 }\end{array}$ & $\begin{array}{l}\text { Hardness } \\
\text { value 3 }\end{array}$ \\
\hline Laser Power: & & & & \\
60w & & & & \\
Layer Thickness: & 1 & 132 & 145 & \\
0.8mm & & & \\
Scan Spacing: & & & \\
0.10 & & & \\
Laser Power: 64 & & & \\
w & & & \\
Layer Thickness: & 2 & & \\
0.10 mm & & & \\
Scan Spacing: & & & \\
0.10 & & & \\
Laser Power: 60 & & & \\
w & & & \\
Layer Thickness: & 3 & & \\
0.10 mm & & & \\
Scan Spacing: & & & \\
0.08 mm & & & \\
\hline
\end{tabular}

\section{Microstructure Test}

The microstructure test was carried out to find the distribution of alpha and beta particles on the fabricated part. The following images show the distribution of alpha particles in a matrix of beta particles. From the figure the structured observed non uniform distribution of alpha and beta particles. The first image shows a uniform distribution of alpha and beta particles, whereas the second image shows a non-uniform distribution
(A)

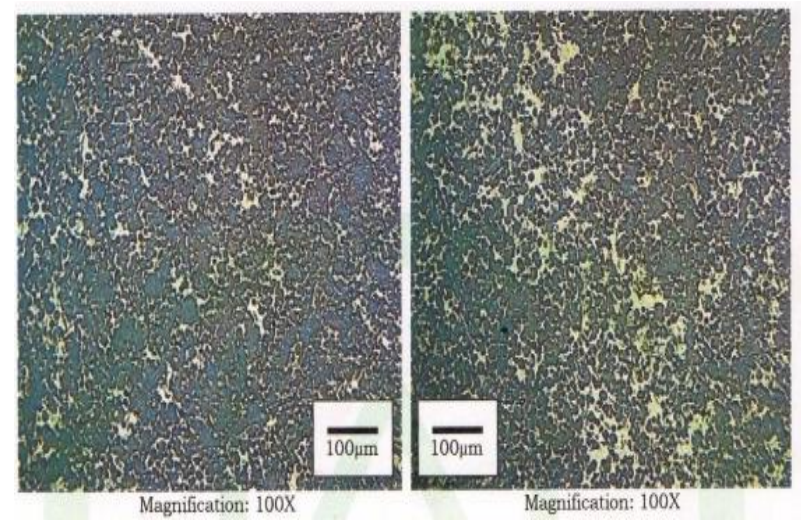

(B)

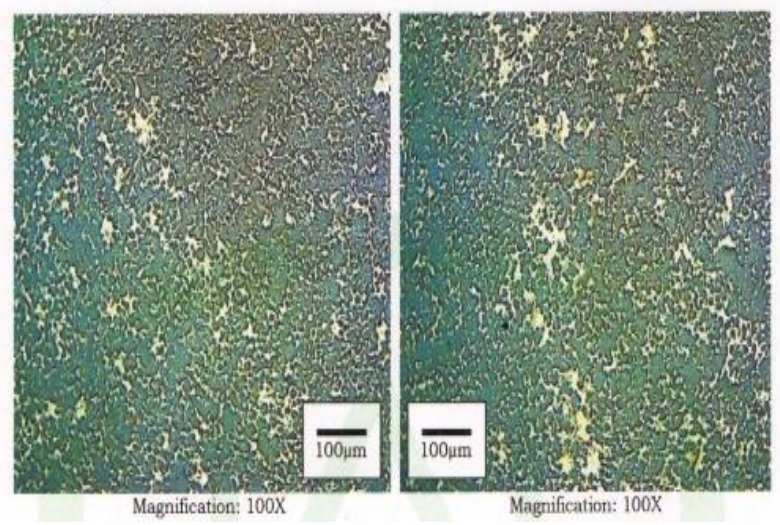

(C)
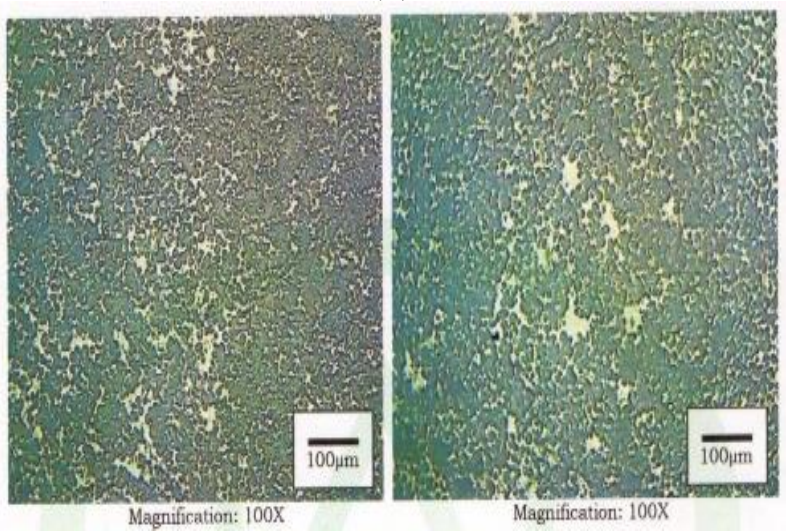

Fig. 4.1: A) Microstructure of Sample 1, B) Microstructure of Sample 2, C) Microstructure of Sample 3.

From the above images the hardness value will vary from place to place due to the non-uniform distribution of powder particles. In order to reduce the non-uniformity of powder particles and to get a uniform distribution the compaction of the powder particle should be increased. By reducing the scan spacing also we can reduce the non-uniformity in the particle distribution.

\section{Results and discussion}

In the study of properties of part fabricated by selective laser sintering process, the web gland of LPG valve was designed and fabricated by casting and selective laser sintering process. The web was manufactured by selective laser sintering process by varying control parameters like laser energy, layer thickness, and scan spacing were varied. The hardness and microstructure test was carried out individually for each samples. From the result of hardness form casting process and selective laser sintering process was found to be in the allowable limit and the hardness value of selective laser sintering process was found to be higher in certain samples. The 
below table shows the various hardness values in comparison between casting process and selective laser sintering process.

Table 4: Hardness Values of Casting and SLS Samples

\begin{tabular}{llll}
\hline Casting Sample & SLS sample 1 & SLS Sample 2 & SLS Sample 3 \\
\hline 168 & 167 & 189 & 180 \\
\hline
\end{tabular}

\section{Conclusion}

From the table 3 the hardness value of sample1 was obtained from the default values. The hardness value of sample 2 is obtained by varying the laser energy and layer thickness. The hardness value of sample3 is obtained by varying the scan spacing and layer thickness. From the hardness values of three samples it was found that the hardness varies place to place in the same component. So microstructure of the part was studied from the microstructure of sample1, sample 2 and sample 3 it was found that there are uniform and non-uniform distribution in the alpha and beta particle. From the images of micro structure it was found that when the scan spacing and compactness was decreased the distribution of powder particle are streamlined so that the hardness of the part increases due to uniform distribution.

\section{References}

[1] Baufeld Bernd, Biest, Omar, Gault Rosemary," Additive manufac turing of Ti-6Al-4V components by shaped metal deposition: Microstructure and mechanical properties", journal on materials and design, Vol.31, pp.106-111, 2010.

[2] Eli Jerby, Yehuda Meir, Alon Salzberg, Eli Aharoni. , 'Incremental metal-powder solidification by localized microwave heating and its potential for additive manufacturing," journal on additive manufacturing, Vol.6, pp.53-66, 2015.

[3] Majeswki, Vasquez, Haworth, "A targeted material selection process for polymers in laser sintering", journal on additive manufacturing, Vol.4, pp.127-138, 2014.

[4] Shifeng Wen, Qiwen Shen, Qingsong Wei, “Material optimization and post-processing of sand moulds manufactured by the selective laser sintering of binder-coated Al2O3 sands," journals of material processing technology, vol.225, pp.93-102,2015.

[5] Tatsuaki Fukumoto, Ayato Koizumi, Mohd Rizal Alkahari, Rui Anayama, "Permeability and strength of a porous metal structure fabricated by additive manufacturing,' Journal of Materials Processing Technology, Vol.219, pp.10-16, 2014.

[6] Nicolas Gardana, Alexandre Schneiderb (2014), "Topological optimization of internal patterns and support in additive manufacturing," Journal of Manufacturing Systems.

[7] Remi Ponche, Olivier Kerbrat, Pascal Mognol, Jean-Yves Hascoet (2014), 'A novel methodology of design for Additive Manufacturing applied to Additive Laser Manufacturing process," Robotics and Computer-Integrated Manufacturing, Vol.30, pp.389-398.

[8] Shifeng Wen, Qiwen Shen, Qingsong Wei. (2015), "Material optimization and post-processing of sand moulds manufactured by the selective laser sintering of binder-coated $\mathrm{Al} 2 \mathrm{O} 3$ sands," journals of material processing technology, vol.225, pp.93-102.

[9] Stwora, Skrabalak. G (2013), "Influence of selected parameters of Selective Laser Sintering process on properties of sintered materials," Journal of achievement in materials and manufacturing engineering, Vol.61, pp.375-380.

[10] Donghong Ding, Zengxi Pan, Dominic Cuiuri, Huijun Li. (2015), '”A practical path planning methodology for wire and arc additive manufacturing of thin-walled structures,' Journal on Robotics and Computer-Integrated Manufacturing, vol.34, pp.8-10. 